\title{
Salience of rape affects self-esteem: The moderating role of gender and rape myth acceptance
}

\author{
GERD BOHNER \\ Universität Mannheim, Germany \\ CHRISTINA WEISBROD \\ Universität Heidelberg, Germany \\ PAULA RAYMOND and ALEXANDRA BARZVI \\ New York University, New York, U.S.A. \\ and \\ NORBERT SCHWARZ \\ University of Michigan, Ann Arbor, U.S.A.
}

\section{Abstract}

In two experiments, conducted in Germany and the U.S.A., it was found that exposure to a rape report lowered self-esteem and positive affect in women who do not accept 'rape myths' (stereotypical beliefs which blame the victim and exonerate the rapist; Burt, 1980). Men high in rape myth acceptance ( $R M A)$ showed an increase in positive affect and self-esteem as a function of exposure to rape; men low in RMA and women high in RMA were largely unaffected. Both experiments demonstrated that these effects were specific to rape, as opposed to violence in general. These results support the feminist hypothesis that the threat of rape serves the function to exert social control over women and to sustain men's dominance. Potential cognitive mechanisms mediating the observed effects are discussed.

Experiment 1 was conducted by Christina Weisbrod as part of her diploma thesis at the University of Heidelberg, under the supervision of Gerd Bohner and Stefan E. Hormuth, whose helpful advice are gratefully acknowledged.

Part of this research and preparation of the manuscript were supported by a Feodor Lynen research fellowship of the Alexander von Humboldt foundation to Gerd Bohner. Alexandra Barzvi and Paula Raymond contributed equally to this research; order of their authorship was determined by a coin toss.

The authors would like to thank Klaus Fiedler for his thoughtful comments on a previous draft, and Erich Wallenwein for his organizational support in data collection for Experiment 1.

Correspondence concerning this article should be addressed to Gerd Bohner, Universität Mannheim, Sozialpsychologie, Postfach 1034 62, D-6800 Mannheim, Germany. 


\section{INTRODUCTION}

How are non-raped women affected by the social reality of rape? According to feminist writers, violence against women, culminating in rape, is assumed to intimidate women in general, whether personally victimized or not (e.g. Brownmiller, 1975; London Rape Crisis Centre, 1984). This has been most pointedly proposed by Susan Brownmiller, who argued that rape 'is nothing more or less than a conscious process of intimidation by which all men keep all women in a state of fear' (Brownmiller, 1975, p. 15). In general, it is hypothesized that rape, together with the 'rules' women are taught 'to avoid rape', has the function of exerting social control which preserves men's power over women and sustains the status quo of male dominance.

Specifically, the threat of rape is suspected to impair women's self-esteem, to weaken their trust in others, and to decrease their perception of personal control, with the consequence that women are more likely to conform with traditional sex-role expectations, in both their beliefs and their behaviour.

A number of correlational studies yielded results compatible with these assumptions. For example, research showed a direct relationship between fear of rape and the extent to which women impose behavioural constraints upon themselves (Riger and Gordon, 1981), and demonstrated a negative association between rape rate and gender equality across societies (Baron and Straus, 1986; Sanday, 1981). However, these correlational studies do not allow conclusions about the hypothesized causal impact of rape prevalence on women's self-esteem, sex-role attitudes, and behaviour.

Although a direct test of this hypothesis is impossible, manipulating the cognitive accessibility of rape constitutes a feasible alternative ( $c f$. Schwarz and Strack, 1981; Schwarz, 1987). The rationale which underlies this approach is that if rape has a causal influence, its impact should be stronger when the representation of rape is highly accessible in memory at the time women make self-esteem or related judgments, than when it is not. Schwarz and Brand (1983) reported a study which employed this methodology. Female college students completed a personality questionnaire either before or after they had read a realistic description of a rape incident. Women who had first read about the rape incident reported lower self-esteem, lower trust in other people, and more traditional sex-role attitudes than women in the control group, who had not been exposed to a description of the rape incident.

Schwarz and Brand (1983) also assessed their subjects' enduring rape myth acceptance (RMA; Costin and Schwarz, 1987). Rape myths are stereotypical assumptions about rape, rape victims, and rapists which put the blame on the victim and/or vindicate the rapist's actions (e.g. 'a woman who is raped asked for it'; 'most rapists are oversexed'; Burt, 1980; Costin and Schwarz, 1987). Schwarz and Brand proposed that women who believe in rape myths might be more strongly affected by the salience of rape than women who do not accept rape myths, because the former have been shown to attribute greater responsibility to the raped woman (for an overview $c f$. Krahé, 1991). However, no interaction of RMA and the salience manipulation was detected.

The Schwarz and Brand (1983) study was the first to establish a causal relationship between rape and women's self-evaluations and attitudes. However, it was not conclu- 
sive with respect to a number of questions, which will be empirically addressed in the present article.

\section{How specific is the impact of rape accessibility?}

According to feminist theory, at least some of the adverse effects of rape accessibility should be gender-specific. This is most clearly the case for the impact of rape on self-esteem: If rape serves the function of 'showing women their place in society', one should expect a decrease in women's but not in men's self-esteem after exposure to a rape description. A strong version of Brownmiller's argument would even hold that men might exhibit a more pasitive view of themselves, and report higher selfesteem, when rape is salient than when it is not.

It is less clear whether the effects of rape on interpersonal trust and sex-role attitudes are likely to be gender-specific. Low interpersonal trust and endorsement of traditional gender roles may be seen as part of the value system of a male-dominated culture, and might therefore be affected similarly in both women and men as a function of exposure to rape. To determine whether the effects of rape are gender-specific, both women and men should be included as subjects in one experimental design.

Furthermore, it seems crucial to examine if the results reported by Schwarz and Brand (1983) represent a specific response to rape, as opposed to a more general reaction to interpersonal violence or crime. Exposure to negative material (like crime, accidents, or natural disasters) has been shown to temporarily impair a person's affective state (e.g. Johnson and Tversky, 1983), which may in turn influence evaluative judgments about the self (Schwarz, 1990; Schwarz and Clore, 1988). Therefore, the impact of rape descriptions should be contrasted with the influence of other descriptions of violence, which are comparably negative in tone but unlikely to activate thoughts about rape.

\section{The role of enduring beliefs about rape}

Enduring beliefs about rape might affect a person's self-evaluation either directly or indirectly. High acceptance of rape myths may be directly associated with lower self-esteem (Burt, 1980), independent of temporary accessibility of rape. But it may also moderate the impact of rape accessibility, by either increasing (as suggested by Schwarz and Brand) or decreasing its influence.

Although non-significant, the result pattern reported by Schwarz and Brand (1983) suggested that when rape was salient, women with stronger belief in rape myths tended to report lower self-esteem than women with weaker belief in rape myths. The prediction of a reversed pattern, however, seems at least equally plausible. Rape myths do not only imply greater responsibility of women, but also indirectly suggest that women can avoid being raped if they follow certain rules (e.g. concerning a 'decent' way to dress or behave in public). Furthermore, belief in rape myths comprises a stereotype of the 'typical rape victim', implying that only women who conform to this stereotype are in danger of being victimized.

Therefore, a woman who endorses rape myths may assume (a) that she is an unlikely target of rape to begin with, and/or (b) that she can personally avoid rape as long as she follows certain rules. A woman who does not endorse rape myths, however, should conceive of rape as a realistic threat to all women, including herself, 
and should be unlikely to overestimate her own control. This reasoning is supported by the results of a recent correlational study showing that perceived vulnerability (i.e. subjective likelihood of being raped) was negatively associated with rape myth acceptance in U.S. college undergraduates (Tabone, Pardine and Salzano, 1992).

The failure to find a stronger impact of rape accessibility on women low (as opposed to high) in RMA in the experiment of Schwarz and Brand (1983) may be due to specific characteristics of their experimental material which blatantly contradicted certain aspects of the rape myth: For example, the victim's helplessness was graphically described, and subjects were instructed to empathize by imagining themselves in the place of the victim (pp. 72-73).

To address the issues discussed above, we conducted two experiments, extending the original design of Schwarz and Brand (1983) by investigating both men and women, and by comparing the effects of rape with those of another violent crime. The potentially moderating role of individuals' chronic beliefs about rape was examined by comparing subjects who were high versus low in rape myth acceptance. To render an impact of chronic rape myth acceptance more likely, a less vivid rape vignette was employed, and subjects were not instructed to empathize with the victim.

\section{EXPERIMENT 1}

\section{Method}

\section{Subjects}

Thirty-five female and 50 male students at a vocational school in Mannheim, Germany, participated. Subjects were in training for occupations in technical drawing or as industrial mechanics. Their age ranged from 15 to 24 years, with a mean of 18.5 years. Most subjects (64 per cent) were 18 or 19 years old. The experimental sessions took place during regular class hours in the fall of 1990 , with 14 to 25 subjects per session.

\section{Procedure and design}

The female experimenter presented the experiment as two independent studies, dealing with 'text comprehension' and the validation of various personality scales, respectively. To enhance the credibility of this cover story, we used two separate, highly dissimilar booklets, each bearing the letterhead of a different university. Subjects first read two paragraphs, presented as newspaper articles, and answered five questions pertaining to each paragraph. The first paragraph described a sports event and was identical for all subjects; the second paragraph's content constituted the major independent variable, salience of crime. It either described a no-crime topic (a report about storks in a local park), a rape, or a violent assault (see Appendix A for an English translation of the two crime-related paragraphs). Subjects were randomly assigned to one of these three conditions, resulting in a 2 (salience of crime) $\times 2$ (sex of subject) design with 11 to 16 subjects per cell.

The booklets for 'the second study' contained the dependent variables and the rape myth acceptance scale (Costin and Schwarz, 1987). When subjects had filled out the second booklet, they were probed for suspicion and debriefed. No subject 
reported any suspicion with respect to the authenticity of the alleged newspaper articles or a possible connection between the two parts of the experimental session. The responses of one male subject were excluded from analysis because he failed to complete part of the questionnaire.

\section{Materials}

The alleged 'newspaper articles' were ascribed to a well-known, serious local newspaper and dated about three months before the experimental session. They were designed to prime no violence-related thoughts, thoughts about rape, or thoughts about violence but not rape. Therefore, in the assault condition, the victim was male. The victim's age in both crime-related vignettes matched the subjects' mean age of 19. To enhance subjects' attention, they were asked to answer five questions about the content of each article they read ${ }^{1}$.

In the second part of the experiment, two self-esteem scales were administered: general self-esteem (GSE; e.g. 'I can be proud of myself'), and social confidence (SOC; e.g. 'I often worry about whether other people like to be with me'). These served as the major dependent variables. The GSE scale consisted of eight items, combining the four items which constitute the 'global' subscale of a German scale on 'domain-specific self-satisfaction' (Hormuth and Lalli, 1988), and the four items loading highest on the 'general self-esteem' factor of the revised feelings of inadequacy scale (Fleming and Watts, 1980) ${ }^{2}$. The SOC scale comprised the seven items of the revised feelings of inadequacy scale loading highest on the 'social confidence' factor (Fleming and Watts, 1980; see footnote 2).

In addition, we included scales on interpersonal trust (IPT; five items adapted from a scale by Amelang, Gold and Külbel, 1984; e.g. "there are only few people one can rely on'), attitudes toward women (ATW; 20 items; Costin, 1985; Costin and Schwarz, 1987; based on a scale developed by Spence and Helmreich, 1972; e.g. 'a woman's social status should be determined by the status of her husband'), affective state (AFF; 14 adjectives selected from a scale by Abele-Brehm and Brehm, 1986; e.g. 'carefree', 'depressed'), and rape myth acceptance (RMA; 20 items; Costin, 1985; Costin and Schwarz, 1987; based on a scale developed by Feild, 1978; e.g. 'women often provoke rape by their appearance and behaviour'). The ATW scale assesses sex-role related attitudes on a continuum from 'liberal / egalitarian' to 'conservative / patriarchal'. The affect scale measures momentary mood on a continuum from 'positive-relaxed' to 'negative-tense'. Most scales, except IPT, were satisfactory to high in internal consistency. Cronbach's alpha for each scale and intercorrelations of all scales are reported in Table 1.

\footnotetext{
${ }^{1}$ For the crime-related paragraphs, these questions pertained to the victim's name and age, number of perpetrators, the weapon used, and an estimate of rape (assault) incidence per year in the state of Baden-Württemberg. For the four factual questions, recall was good and independent of experimental conditions, with one exception: The number of assailants was recalled better in the rape (100 per cent) than in the assault ( 79 per cent) condition. We attribute this difference to the fact that the number of assailants was explicitly mentioned only once in the assault condition, but three times in the rape condition (see Appendix A). Overall, the recall data suggest that subjects paid sufficient attention to experimental materials.

${ }^{2}$ A German translation of these items was adapted from: Grabitz-Gniech, G. (undated). Bericht über eine Analyse von sieben Persönlichkeitsfragebogen [Report about an analysis of seven personality questionnaires]. Universität Mannheim, Germany: Fakultät für Sozialwissenschaften.
} 
Table 1. Internal consistencies and intercorrelations of scales used in Experiment 1

\begin{tabular}{lcllllll}
\hline & & \multicolumn{5}{c}{ Pearson correlation coefficients } \\
Scale* & Cronbach's Alpha & GSE & SOC & IPT & ATW & AFF \\
\hline GSE & 0.76 & - & & & & \\
SOC & 0.72 & $0.72 \ddagger$ & - & & & \\
IPT & 0.48 & 0.18 & 0.15 & - & & \\
ATW $\dagger$ & 0.84 & $0.30 \S$ & $0.31 \S$ & -0.05 & - & \\
AFF & 0.91 & 0.25 & 0.16 & 0.16 & -0.07 & - \\
RMA & 0.82 & $0.29 \S$ & 0.19 & -0.15 & $0.68 \ddagger$ & -0.01 \\
\hline
\end{tabular}

All coefficients are based on $N=81$.

* GSE = General Self-Esteem, SOC $=$ Social Confidence, IPT = Interpersonal Trust, ATW = Attitudes toward Women, AFF = Affective State, RMA = Rape Myth Acceptance.

$\dagger$ ATW is scored so that higher values indicate more conservative attitudes.

$\ddagger p<0.001 . \S p<0.01$.

The GSE, SOC, IPT, and ATW items were presented in random order, followed by the AFF and RMA scales. Endorsement of rape myths was assessed at the end of the experimental session to minimize the potential impact of the salience manipulation. On all measures, subjects were asked to indicate their agreement with each item on a scale from 1 , 'completely untrue', to 7 , 'completely true'.

\section{Formation of groups high versus low in rape myth acceptance}

As in previous studies (Costin, 1985; Costin and Schwarz, 1987), men reported higher RMA $(M=3.42)$ than women $(M=2.67), t(78)=4.58, p<0.001$. Planned comparisons further revealed that subjects who had read the rape text tended to report lower RMA $(M=2.91)$ than subjects who had read either the neutral text $(M$ $=3.27)$ or the assault text $(M=3.13), t(78)=1.69, p<0.10$. To account for these differences, we computed residual scores of RMA from which the variance explained by gender and experimental condition had been removed. A median split was performed on this residualized variable to define groups high and low in $R M A$. Means for the high and low RMA groups were 3.31 and 2.12, respectively, for women, and 3.90 and 2.87 , respectively, for men.

\section{Analysis}

In a first step, means of the assault condition were separately compared with those of the no-crime condition, to detect any potential effects of salience of violence that were nonspecific to rape. If this analysis yielded no significant results, a-priori contrasts (Rosenthal and Rosnow, 1985) were performed to test the specific hypotheses about the influence of rape, comparing means of the rape condition with those of the no-crime and assault conditions combined (see Table 2 for contrast weights). If any effects of assault were detected, means of the rape conditions were separately compared with those of the no-crime condition. All main effects and interactions not involving the salience factor (i.e. RMA, sex of subject, and RMA by sex of subject) correspond to those in standard analysis of variance, but for the sake of consistency, $t$-statistics will be reported throughout. 
Table 2. Contrast weights used in data analysis

\begin{tabular}{llrrrrrr}
\hline \multirow{2}{*}{ Effect } & Gender & $\mathrm{N} \dagger$ & $\mathrm{A} \dagger$ & $\mathrm{R} \dagger$ & $\mathrm{N}$ & $\mathrm{H}$ & $\mathrm{R}$ \\
\hline Rape $\times \mathrm{RMA}$ & Female & 1 & 1 & -2 & -1 & -1 & 2 \\
$\times$ Gender & Male & -1 & -1 & 2 & 1 & 1 & -2 \\
Rape $\times$ Gender & Female & 1 & 1 & -2 & 1 & 1 & -2 \\
& Male & -1 & -1 & 2 & -1 & -1 & 2 \\
Rape $\times$ RMA & Female & 1 & 1 & -2 & -1 & -2 & 2 \\
& Male & 1 & 1 & -2 & -1 & -1 & 2 \\
Rape & Female & 1 & 1 & -2 & 1 & 1 & -2 \\
& Male & 1 & 1 & -2 & 1 & 1 & -2 \\
\hline
\end{tabular}

* $\mathrm{RMA}=$ rape myth acceptance.

$\dagger \mathrm{N}=$ no crime salient, $\mathrm{A}=$ assault salient, $\mathrm{R}=$ rape salient.

\section{Results}

\section{Effects of salience of assault}

For the affect scale, a marginal three-way interaction emerged, $t(71)=-1.73, p$ $<0.09^{3}$, reflecting a negative effect of assault on women high in RMA, $t(71)=$ $1.95, p<0.06$ ( $p>0.24$ for all other simple effects). Effects of rape salience on affective state reported below are therefore based on comparisons of the rape and no-crime conditions. No other dependent variable was significantly affected by the salience of assault, all $p>0.19$.

\section{Effects of salience of rape}

General self-esteem Surprisingly, subjects high in RMA reported higher general self-esteem $(M=5.27)$ than subjects low in RMA $(M=4.72), t(43.3)=2.23$, $p<0.04^{4}$. Moreover, we found significant interactions of salience of rape and gender, $t(49.0)=2.40, p<0.025$, and of salience of rape and RMA, $t(49.0)=2.38$, $p<0.025$. As expected, simple effects analyses within combinations of gender and RMA indicated lower general self-esteem in the rape condition for women low in RMA, $t(11.6)=2.74, p<0.02$, supporting the key hypothesis of the present paper. In contrast, women high in RMA were unaffected, $t(6.7)=-1.22, p>0.26$ (see Table 3 for means). Conversely, men high in RMA reported higher general self-esteem when they had read the rape text than when they had not, $t(21.4)=-2.35, p<$ 0.03 , indicating that these men's self-esteem benefitted from exposure to a rape report. In contrast, men low in RMA were unaffected by exposure to the rape text, $t(16.8)$ $=-1.03, p>0.32$.

Social confidence Contrast analysis revealed a marginal three-way interaction, $t(72)$ $=1.91, p<0.07$. Separate comparisons within the combinations of gender and RMA showed that women low in RMA reported lower social confidence when rape was salient than when it was not, $t(72)=2.05, p<0.05$, whereas women high

\footnotetext{
${ }^{3}$ Tests based on $N=83$ because of missing data.

${ }^{4}$ Because of inhomogeneity of variances, $t$-values for this dependent variable are based on separate variance estimates.
} 
Table 3. Means of dependent variables as a function of salience of rape, gender, and rape myth acceptance (Experiment 1: German sample)

\begin{tabular}{llcccccc}
\hline \multirow{2}{*}{ Dependent variable } & Gender & $\mathrm{N} \dagger$ & $\mathrm{A} \dagger$ & $\mathrm{R} \dagger$ & $\mathrm{N}$ & $\mathrm{A}$ & $\mathrm{R}$ \\
\hline General self-esteem & Female & 5.41 & 4.98 & 4.38 & 5.06 & 4.72 & 5.29 \\
& Male & 4.50 & 4.56 & 4.93 & 5.49 & 4.80 & 5.94 \\
Social confidence & Female & 4.99 & 4.55 & 3.89 & 3.86 & 3.40 & 4.90 \\
& Male & 4.07 & 4.11 & 4.12 & 4.55 & 4.27 & 4.82 \\
Interpersonal trust & Female & 3.30 & 3.73 & 3.18 & 2.99 & 3.24 & 3.00 \\
& Male & 2.69 & 2.85 & 3.17 & 2.55 & 2.72 & 3.00 \\
Attitudes toward & Female & 2.65 & 2.33 & 2.30 & 3.01 & 2.92 & 2.82 \\
women & Male & 2.98 & 2.96 & 3.09 & 3.83 & 3.82 & 3.80 \\
Affective state & Female & 5.54 & 5.31 & 5.14 & 5.09 & 3.89 & 4.95 \\
& Male & 5.44 & 4.97 & 4.10 & 4.52 & 5.15 & 5.43 \\
\hline
\end{tabular}

Higher scores indicate greater general self-esteem, higher social confidence, more traditional attitudes towards women, greater interpersonal trust, and more positive affect, respectively.

* $\mathrm{RMA}=$ rape myth acceptance

$\dagger \mathrm{N}=$ no crime salient, $\mathrm{A}=$ assault salient, $\mathrm{R}=$ rape salient.

in RMA showed a reverse pattern, $t(72)=-2.14, p<0.04$. Men's reports of social confidence, on the other hand, were unaffected, $t(72)=-0.78, p>0.43$ (see Table 3 for means).

Interpersonal trust Female subjects reported higher trust in people ( $M=3.24$ ) than male subjects $(M=2.82), t(72)=2.04, p<0.05$. No other effects were reliable, all $p>0.16$.

Attitudes toward women In agreement with previous research, sex-role related attitudes covaried with subjects' gender and rape myth acceptance. Women reported more liberal attitudes towards women's social roles $(M=2.64$; range from $1=$ 'liberal' to $7=$ 'conservative') than did men $(M=3.43), t(72)=4.40, p<0.001$. Subjects low in RMA reported more liberal attitudes $(M=2.72)$ than subjects high in RMA $(M=3.47), t(72)=3.83, p<0.001$. No effects involving the salience manipulation were reliable, all $p>0.34$.

Affective state Comparisons of the rape and no-crime conditions yielded an interaction of salience of rape and RMA, $t(71)=2.04, p<0.05$, and a trend towards a three-way interaction, $t(71)=-1.61, p=0.11$. Separate analyses for men and women suggest that the interaction of salience of rape and RMA was uniquely due to male subjects, $t(71)=2.96, p<0.005$ (female subjects: $t(71)=0.27$ ). Specifically, men low in $R M A$ who had read the rape paragraph reported feeling worse than men low in RMA who had read the no-crime paragraph, $t(71)=2.42, p<0.02$, whereas a reverse trend was obtained for men high in $R M A, t(72)=-1.74, p<$ 0.09 (see Table 3 for means).

\section{Discussion}

These results partly replicate and extend the findings of Schwarz and Brand (1983). They indicate that high accessibility of rape leads to lower self-esteem in women who do not believe in rape myths. Women who do endorse rape myths seemed 
to be unaffected; they even reported slightly higher social confidence when rape was salient than when it was not salient. In contrast, men, in particular when high on rape myth acceptance, exhibited significantly higher general self-esteem and positive affect when rape was salient, and were otherwise largely unaffected by the salience manipulation.

Furthermore, the observed negative impact on women low in RMA was shown to be specific to rape. It was not a result of greater accessibility of violence in general: Subjects who had been exposed to the description of an assault did not report lower self-esteem than those in the control condition.

A particularly disconcerting aspect of the results is the increase in general selfesteem and in positive affect in those men who were exposed to the rape report and expressed high acceptance of rape myths. This corroborates the claims of feminist researchers that the social reality of rape, in combination with cultural myths about rape, may foster gender inequality (Brownmiller, 1975). Interestingly, those men who held more realistic beliefs about rape (men with low RMA) showed a negative affective reaction to the rape description, but this was not accompanied by any decrements in self-esteem.

Somewhat surprisingly, sex-role attitudes and interpersonal trust were not influenced by accessibility of rape. In the case of interpersonal trust, a potential effect may have gone undetected, because of the low internal consistency of the scale we used. Attitudes toward women, however, were reliably measured but patterned opposite to the findings of Schwarz and Brand (1983).

\section{EXPERIMENT 2}

A second experiment was conducted with the major objective to assess the generality of our findings, studying subjects from a different cultural background. In previous studies (both Schwarz and Brand, 1983; and the present Experiment 1), it had been tacitly assumed that most of the female subjects had not been victims of sexual violence themselves, but no attempt had been made to actually assess subjects' prior experiences. Given the relatively high prevalence of rape and sexual violence against women (e.g. Koss, 1988), it is unclear whether the results of these studies truly represent the impact of rape on non-raped women. To address this issue in Experiment 2 , we asked female subjects about prior experiences of sexual violence. We did not expect the proportion of rape victims in our sample to be sufficiently large for systematic comparisons between non-victims and victims, so we decided to exclude from analysis the data of subjects who reported to have been victims of sexual violence.

\section{Method}

\section{Subjects}

Eighty-four female and 44 male introductory psychology students at New York University participated in Experiment 2 for partial course credit between the fall of 1991 and the spring of 1992. Subjects were randomly assigned to one of three conditions (no crime, rape, assault). Their age ranged from 17 to 27 years, with 
a mean of 18.7 years. As in Experiment 1, most subjects (75.9 per cent) were 18 or 19 years old. The experiment was conducted in mixed-sex group sessions with two to seven subjects, who were separated from each other's view by dividers to minimize interaction.

\section{Procedure}

Subjects learned that they would participate in three separate, unrelated studies on 'impression formation', 'text comprehension', and 'feelings an opinions'. The female experimenter handed out separate booklets for each study. In the first part of the experiment, subjects read the description of a person and were subsequently asked to rate this person on several dimensions. This part was in fact unrelated to the present experiment, and it will not be further discussed. The alleged 'text comprehension' study constituted the salience manipulation. Subjects read a paragraph that either described a neutral event (a model boat race in Central Park), a rape, or a violent assault (see Appendix B for the text of the two crime-related paragraphs). The booklet of the alleged third study contained the dependent variables and the rape myth acceptance scale (Burt, 1980). In addition, female subjects answered three questions pertaining to personal victimization (Burt, 1980). Finally, subjects were probed for suspicion and debriefed.

\section{Materials}

The materials were similar in every relevant aspect to those in Experiment 1. Again, the text paragraph was introduced as a recent newspaper article, and subjects were subsequently asked five questions about it ${ }^{5}$.

As in Experiment 1, general self-esteem (GSE) and social confidence (SOC) served as the major dependent variables. The GSE scale consisted of 11 items, combining the four items of the 'global self-satisfaction' subscale (Hormuth and Lalli, 1988; our translation), and the seven items loading highest on the 'general self-esteem' factor of the revised feelings of inadequacy scale (Fleming and Watts, 1980). The SOC scale comprised the nine items of the revised feelings of inadequacy scale loading highest on the 'social confidence' factor (Fleming and Watts, 1980).

Scales on interpersonal trust (IPT; five items adapted from Rosenberg, 1957; e.g. 'Human nature is fundamentally cooperative'; see Robinson, Shaver and Wrightsman, 1991, pp. 404 406), attitudes toward women (ATW; six items; e.g. 'I believe that home and family should be a priority for women (versus men), taking precedence over other activities'), affective state (AFF; six bipolar adjective scales; e.g. 'good - bad'), and rape myth acceptance (RMA; 15 items; Burt, 1980) were also included.

All scales proved satisfactory to high in internal consistency (see Table 4 for Cronbach's alpha and intercorrelations of all scales). The AFF scale was presented first,

\footnotetext{
${ }^{5}$ For the crime-related paragraphs, these questions pertained to the victim's name, age, and job, the weapon used, and an estimate of how many rapes (assaults) occur in New York City during one year. Overall, subjects' responses to the recall questions indicated good recall ( 90 per cent correct or almost correct), and there were no sex differences. However, the content of the no crime (97 per cent) and rape ( 94 per cent) paragraphs was recalled somewhat better than that of the assault paragraph ( 80 per cent).
} 
followed by the GSE, SOC, IPT, and ATW items, which were presented in random order. As in Experiment 1, the RMA scale was administered last, and subjects were asked to indicate their agreement with each item on a scale from 1 to 7 .

Table 4. Internal consistencies and intercorrelations of scales used in Experiment 2

\begin{tabular}{lcccccc}
\hline & & \multicolumn{5}{c}{ Pearson correlation coefficients } \\
Scale* & Cronbach's Alpha & GSE & SOC & IPT & ATW & AFF \\
\hline GSE & 0.89 & - & & & & \\
SOC & 0.83 & $0.48 \ddagger$ & - & & & \\
IPT & 0.60 & 0.16 & -0.05 & - & & \\
ATW $\dagger$ & 0.63 & 0.03 & -0.07 & 0.13 & - & \\
AFF & 0.83 & $0.54 \ddagger$ & $0.35 \ddagger$ & 0.17 & -0.04 & - \\
RMA & 0.86 & -0.03 & -0.14 & -0.01 & $0.62 \ddagger$ & -0.14 \\
\hline
\end{tabular}

All coefficients are based on $N=88$.

$N=79$;

* GSE $=$ General Self-Esteem, SOC $=$ Social Confidence, $\mathrm{IPT}=$ Interpersonal Trust, ATW $=$ Attitudes toward Women, AFF = Affective State, RMA = Rape Myth Acceptance.

+ ATW is scored so that higher values indicate more conservative attitudes.

$\ddagger p<0.001$.

Finally, female subjects were asked to answer three questions pertaining to prior victimization, which were adapted from Burt (1980, p. 221): 'Have you ever had anyone force sex on you against your will?' (no/yes); 'Have you ever had anyone attempt to force sex on you, but unsuccessfully?' (no/yes); 'Have you ever had sex with someone only because you were afraid physical force would be used against you if you didn't go along?' (no/yes). Because we were interested in effects of rape on non-raped women, we excluded from analysis the data of women who answered 'yes' to any of these questions.

\section{Formation of groups high versus low in $R M A$}

Preliminary analyses indicated that men reported higher rape myth acceptance $(M$ $=2.47)$ than women $(M=2.07), t(83)=2.23, p<0.03$. Furthermore, we found a marginal interaction of salience and gender when the assault and no-crime conditions were compared, $t(83)=1.93, p<0.06$. We therefore computed residual scores of RMA from which the variance due to the specific interaction of gender and salience of assault had been removed. A median split on this residualized variable defined groups high and low in RMA. Raw means of those groups were 2.78 and 1.42 , respectively, for women, and 3.02 and 1.88 , respectively, for men.

\section{Results}

\section{Victimization}

Reported victimization was independent of experimental conditions, $\chi^{2}(4, N=84)$ $=5.12, p>0.27$. Data of 35 (41.6 per cent) women were excluded from analysis 
because these subjects reported to have been victims of attempted ( $n=19 ; 22.6$ per cent) or completed ( $n=16 ; 19.0$ per cent) acts of sexual violence ${ }^{6}$. These figures were considerably higher than those reported by Burt $(1980)^{7}$.

Of the remaining subjects, four (one man in the no crime condition, one woman in the rape condition, and two women in the assault condition) were excluded because they expressed suspicion with regard to the experimental hypotheses. Thus, the final sample consisted of 46 female and 43 male subjects, with $n$ per experimental condition (salience by sex of subject) ranging from 13 to 17 . The strategy of data analysis was identical to the one used in Experiment 1. Means of the major dependent variables, broken down by gender, experimental condition, and RMA are displayed in Table 5.

Table 5. Means of dependent variables as a function of salience of rape, gender, and rape myth acceptance (Experiment 2: U.S. sample)

\begin{tabular}{llcccccc}
\hline & & \multicolumn{3}{c}{ Low RMA* } & \multicolumn{3}{c}{ High RMA } \\
Dependent variable & Gender & $\mathrm{N} \dagger$ & $\mathrm{A} \dagger$ & $\mathrm{R} \uparrow$ & $\mathrm{N}$ & $\mathrm{A}$ & $\mathrm{R}$ \\
\hline General self-esteem & Female & 5.44 & 5.00 & 4.61 & 5.03 & 5.09 & 5.26 \\
& Male & 4.83 & 5.52 & 5.03 & 5.07 & 4.38 & 5.50 \\
Social confidence & Female & 3.56 & 3.43 & 3.19 & 3.00 & 3.78 & 4.11 \\
& Male & 3.91 & 3.20 & 3.27 & 3.46 & 2.99 & 3.93 \\
Interpersonal trust & Female & 2.87 & 3.60 & 3.69 & 3.42 & 3.50 & 4.20 \\
& Male & 3.50 & 3.57 & 3.24 & 3.43 & 3.30 & 3.10 \\
Attitudes toward & Female & 2.96 & 3.15 & 2.88 & 3.73 & 3.56 & 4.64 \\
women & Male & 4.19 & 3.44 & 3.37 & 4.15 & 4.52 & 4.33 \\
Affective state & Female & 5.52 & 4.85 & 4.71 & 4.40 & 4.75 & 5.14 \\
& Male & 4.78 & 6.03 & 4.61 & 4.98 & 4.31 & 5.94 \\
\hline
\end{tabular}

Higher scores indicate more positive affect, greater general self-esteem, higher social confidence, more traditional attitudes towards women, and greater interpersonal trust, respectively.

* RMA = rape myth acceptance

$\dagger \mathbf{N}=$ no crime salient, $A=$ assault salient, $R=$ rape salient.

\footnotetext{
${ }^{6}$ An informal inspection of the data disclosed that responses of 'victims' (persons who answered 'yes' to the first or third victimization question) were often clearly different from the responses of 'attempted victims' (persons who answered 'yes' to the second victimization question, but 'no' to the first and third). For example, 'attempted victims' reported rather high self-esteem after reading the rape text, while 'victims' reported very low self-esteem in this condition. Therefore, it seemed inappropriate to consider these women as an homogeneous group. It would have been desirable to contrast the responses of these two groups with each other and with those of non-victims, but the number of subjects per condition was too low for meaningful statistical analyses.

${ }^{7}$ This difference may in part be a result of divergent methods of assessment. Burt (1980), who interviewed a random sample of Minnesota adults over 18 years of age, found that 26.4 per cent of the women answered 'yes' to one or more of the three victimization questions. We suspect that subjects may be more reluctant to reveal painful and potentially embarrassing experiences in a personal interview than in an experimental questionnaire.

Our victimization results were, however, closely in line with data reported by Koss (1988), who found that 39.3 per cent of the women in a large U.S. college student sample $(N=3187$; mean age 21.4 years; 86 per cent white) reported that they had been victims of attempted or completed sexual coercion and/or rape at least once since the age of 14 .
} 


\section{Effects of salience of assault}

Preliminary analyses testing effects of salience of assault yielded three-way interactions on GSE, $t(77)=1.76, p<0.09$, on ATW, $t(77)=-1.76, p<0.09$, and on AFF, $t(77)=3.16, p<0.003$. Furthermore, a marginal interaction of gender and salience of assault was detected on $\mathrm{SOC}, t(77)=-1.74, p<0.09$.

Simple effects analyses revealed that women were unaffected by the assault manipulation, all $p>0.13$. Men also did not exhibit significant simple effects of salience of assault, with the exception that men low in RMA reported more positive affect when they had read the assault report than when they had read the neutral text, $t(77)=-2.41, p<0.02$. Nevertheless, the analyses reported below for GSE, SOC, ATW, and AFF are based on comparisons of the rape and no-crime conditions.

\section{Effects of salience of rape}

General self-esteem Comparisons of the rape and no-crime conditions yielded no significant overall effects, all $p>0.24$, but the result pattern clearly resembled the one obtained in Experiment 1, as illustrated in Figure 1 (see Table 5 for means).

Social confidence Comparisons of the rape condition with the neutral condition resulted in a significant interaction of salience and RMA, $t(77)=2.40, p<0.02$. Subjects high in RMA reported higher social confidence when rape was salient $(M$ $=4.02)$ than when no crime was salient $(M=3.23), t(77)=-2.03, p<0.05$. This pattern was reversed for subjects low in RMA $\left(M_{\text {rape }}=3.26 ; M_{\text {no-crime }}=3.75\right)$, $t(77)=1.35, p=0.19$. No effects involving sex of subject were obtained, all $p$ $>0.35$.

Interpersonal trust A significant interaction of salience of rape and gender was obtained, $t(77)=-2.08, p<0.05$. Contrary to predictions, women who were exposed to rape reported higher trust in other people $(M=3.92)$ than women who had read either the neutral $(M=3.13)$ or the assault text $(M=3.55), t(77)=-2.00$, $p<0.05$; male subjects were unaffected $\left(M_{\text {rape }}=3.19 ; M_{\text {no-crime }}=3.46 ; M_{\text {assault }}\right.$ $=3.41), t(77)=0.94$.

Attitudes toward women As expected, male subjects reported more conservative attitudes toward women $(M=3.99)$ than did female subjects $(M=3.44), t(77)$ $=2.97, p<0.005$. In addition, subjects who were high in RMA reported more conservative attitudes toward women $(M=4.13)$ than did subjects low in RMA $(M=3.29), t(77)=4.74, p<0.001$.

Comparisons of the rape and no-crime conditions yielded interactions of salience of rape and RMA, $t(77)=2.35, p<0.03$, and of salience of rape and gender, $t(77)=-1.71, p<0.10$. Simple effects analyses revealed that women high in RMA reported more conservative sex-role attitudes when rape was salient than when no crime was salient, $t(77)=-2.08, p<0.05$. Men low in RMA reported more liberal sex-role attitudes when rape was salient than when it was not, $t(77)=1.93, p<$ 0.06 . No reliable effects were detected for either women low in RMA or men high in RMA, both $p>0.35$ (see Table 5 for means).

Thus, the pattern for female subjects replicates Schwarz and Brand (1983), who also found a somewhat greater impact of rape on sex-role attitudes in women who endorsed rape myths.

Affect The data pattern of affective state parallels that of general self-esteem. 
The interaction of salience of rape and RMA was reliable, $t(77)=2.83, p<0.01$. Subjects high in RMA reported more positive affect when rape was salient $(M=$ 5.54) than when it was not $(M=4.69), t(77)=-2.49, p<0.02$; all other $p>$ 0.14 .

\section{Discussion}

Overall, the data pattern in Experiment 2 was slightly more complex than that in Experiment 1. Whereas in Experiment 1, the assault manipulation had hardly any effect, and if so, only on female subjects, it showed some weak impact on male subjects in Experiment 2. However, the simple effects tests within male subjects were largely non-significant, with the exception of a significant increase in positive affect for men low in RMA who had read the assault description. Thus, we may conclude that no reliable negative effects of accessibility of assault were found.

The effects of rape were not as clear-cut as in Experiment 1. The pattern for

Study 1 (Germany)
Women

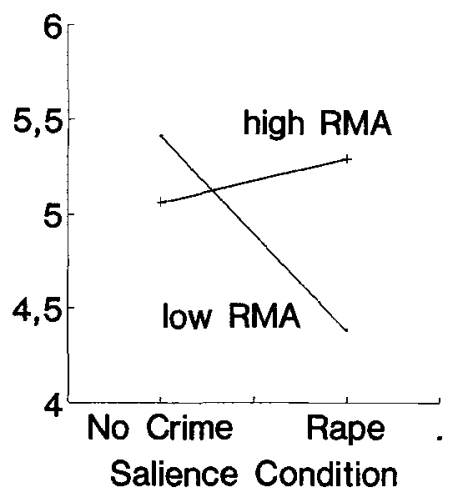

Study 2 (U.S.A.) Women

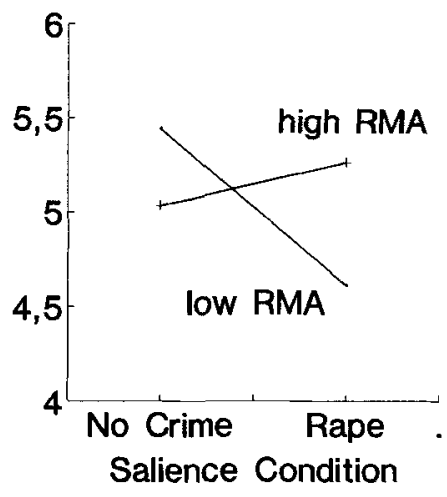

Men

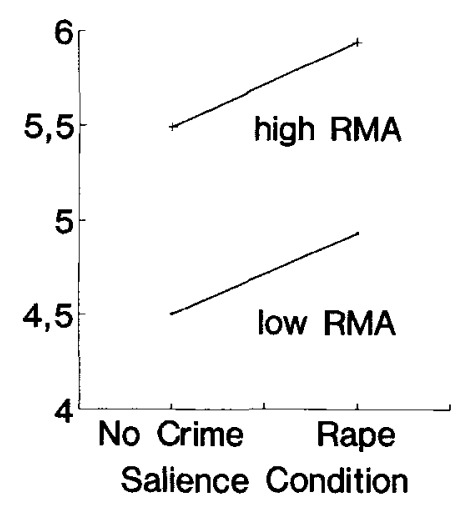

Men

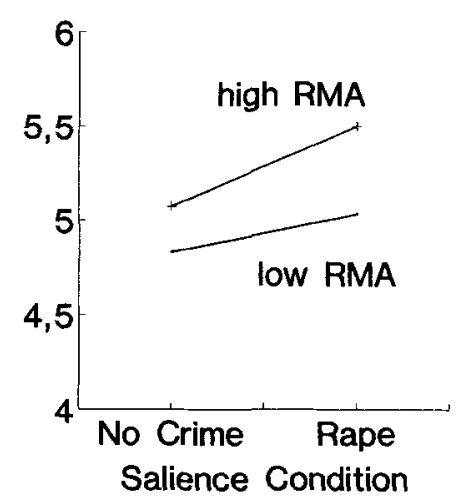

Figure 1. General self-esteem as a function of salience of rape (no crime = no crime salient; rape = rape salient), gender, and rape myth acceptance (RMA) in Experiments 1 (top) and 2 (bottom) 
general self-esteem closely replicated, but failed to reach statistical significance. To get an overall estimate of reliability, we compared the simple contrast effects of salience of rape within each combination of gender and RMA between studies, and computed their combined probability (weighted average $p$ of Experiments 1 and 2 ), given the null hypothesis that

$$
M_{\text {rape }}=\left(1 / 2 \times M_{\text {no-crime }}+1 / 2 \times M_{\text {assault }}\right),
$$

following suggestions by Rosenthal and Rosnow (1984; pp. 369-376). This metaanalysis revealed that the results for general self-esteem did not differ between studies (all $p>0.12$ ). It further showed that, in both studies combined, general self-esteem was significantly lower for females low in RMA who had read the rape text, $z=$ $-2.56, p<0.02$, and higher for males high in RMA who had read the rape text, $z=-2.63, p<0.01$, all other $p>0.29$.

Effects of rape on social confidence seemed independent of gender in Experiment 2. Subjects low in RMA reported lower social confidence when rape (versus no crime) was salient, whereas subjects high in RMA showed the opposite effect. A comparison of Experiments 1 and 2 again showed that results did not differ between studies, all $p>0.33$. The combined probability levels indicate a trend towards a decrease in social confidence as a function of rape for low RMA women, $z=-1.85$, $p<0.07$, but not for low RMA men, $z=-0.41$, and an increase in social confidence for both high RMA women, $z=2.51, p<0.02$, and high RMA men, $z=1.78$, $p<0.08$.

Thus, the two major self-esteem scales yielded consistent results across the two studies conducted in Germany and the United States. They support the notion that women who hold realistic beliefs about rape are negatively affected by exposure to rape descriptions. This pattern seems to be independent of subjects' cultural background, and was obtained even when the data of subjects who reported prior victimization were excluded from analysis.

Subjects' affective state was more strongly influenced by experimental conditions in Experiment 2 than in Experiment 1. This may be due to the fact that affect was assessed immediately after exposure to the experimental manipulation in Experiment 2. Because in Experiment 2, separate effects of assault had been detected, a metaanalytic comparison between the two studies focused on differences between the rape and no-crime conditions. Again, no significant differences between studies were found, all $p>0.15$. The combined probability levels show a pattern closely parallel to that of social confidence, indicating a trend towards less positive affect as a function of rape for low RMA women, $z=-1.71, p<0.09$, but not for low RMA men, $z=-0.98, p>0.32$, and an increase in positive affect for both high RMA women, $z=1.87, p<0.07$, and high RMA men, $z=2.60, p<0.01$.

\section{GENERAL DISCUSSION}

Despite differences in the cultural and educational background of subjects, the two studies yielded strikingly similar results. With respect to self-esteem, they replicated and extended the findings of Schwarz and Brand (1983). The patterns of two scales measuring different aspects of self-esteem yielded converging evidence that high accessibility of rape leads to lower self-esteem in women who do not endorse rape myths. 
Women who believe in rape myths were not negatively affected; they even exhibited higher social confidence when they had been confronted with rape than when they had not.

Furthermore, the combined results of the two studies support the unsettling notion of an increase in general self-esteem and in positive affect in men who believe in rape myths and were exposed to the rape report. This corroborates the claims of feminist researchers that the social reality of rape, in combination with cultural myths about rape, fosters gender inequality (Brownmiller, 1975).

Taken together, the results for self-esteem and affect largely support feminist analyses (Brownmiller, 1975). They seem to reflect a negative impact of rape on the self-concept of women who were not themselves victims of rape. They also indicate, however, that not all women are negatively affected to the same degree. If women's enduring beliefs about rape support rape myths, they seem to be immune against the negative impact of rape to a certain extent. This finding is compatible with the correlational observation that women who accept rape myths perceive their own risk of becoming a rape victim to be lower (Tabone et al., 1992).

This suggests that women's acceptance of rape myths, which are anti-women in nature, may serve a self-protecting function, allowing women to maintain an 'illusion of control' (Langer, 1975) over the threat of rape. In general, however, rape myth acceptance seems to be negatively correlated with self-esteem (Burt, 1980), which is also reflected in the results of our 'no crime' control conditions.

Finally, the impact of rape on self-esteem seems to reflect a specific effect rather than a general consequence of being exposed to violent content. This can be concluded from the fact that we did not find parallel effects of assault on either women's or men's self-esteem.

With respect to other dependent variables, the results of Schwarz and Brand (1983) were not replicated. Interpersonal trust was not found to decrease when rape was salient; it even showed an opposite effect in the U.S. sample. At present, we have no explanation for this unexpected result. Attitudes toward women did become more conservative as a function of rape, but this effect occurred only in the U.S. sample, and was specific to women who accept rape myths. Thus, a-priori differences in sex-role attitudes between women high versus low in RMA seemed to become more extreme when subjects had been confronted with rape. It is presently unclear why this effect did not emerge in the German sample.

What are the cognitive mechanisms involved in the effects of rape on self-esteem and affect? We propose that a person's enduring beliefs about rape serve as a cognitive schema in interpreting incoming information about rape. If a woman's schema includes beliefs like 'any woman can be raped', which indicate low rape myth acceptance, she is more likely to perceive information about rape as a potential threat to herself, and is negatively affected. If, however, a woman's schema contains beliefs like 'women who are raped are asking for it', indicative of high rape myth acceptance, she should be likely to exclude herself from the category of potential rape victims (cf. Schwarz and Bless, 1992). She may thus interpret information about rape as a potential threat to other women, but not herself, which by contrast may result in more positive self-esteem.

Men should generally exclude themselves from the category of potential victims because of their gender, and should not be negatively affected, regardless of their enduring beliefs about rape. But this alone cannot explain why self-esteem and posit- 
ive affect increased particularly in men who did endorse rape myths. It is possible that these men were less likely to perceive the act of rape as a despicable crime, but rather as a 'rightful' act of male dominance. Thus, identification with the rapist may have resulted in more positive affect and self-esteem.

A different process assumption, however, may also account for the reactions of male subjects high in RMA, if we presume that these men did perceive the rape they read about as a rape. Guided by their 'rape myth schema', they might have been particularly likely to categorize the rapist as deviant. Perceiving themselves in contrast to 'the abnormal rapist' might have led to more positive judgments of self-esteem.

Further research is necessary to evaluate these divergent process assumptions. This research might benefit from a more differentiated view of rape myths and the way in which they may guide social perception and judgment. In this regard, it should be useful to distinguish between (a) beliefs about the act of rape, (b) beliefs about rape victims, and (c) beliefs about rapists, and to assess these constructs separately.

Finally, our results have implications for understanding the effects of media descriptions of rape. They demonstrate that exposure to one relatively pallid description of a rape incident can have a profound influence on women's self-esteem. It seems plausible that the multiple exposure to rape accounts in television and newspapers, which are often quite graphic, have even more detrimental effects. Ironically, these effects seem to hurt primarily those women who maintain a realistic view of the threat of rape. Evidently then, the social reality of rape does serve the function of 'showing women their place in society'.

\section{REFERENCES}

Abele-Brehm, A. and Brehm, W. (1986). 'Zur Konzeptualisierung und Messung von Befindlichkeit: Die Entwicklung der Befindlickeitsskalen (BFS)', Diagnostica, 32: 209-228.

Amelang, M., Gold, A. and Kübel, E. (1984). 'Über einige Erfahrungen mit einer deutschsprachigen Skala zur Erfassung zwischenmenschlichen Vertrauens', Diagnostica, 30: 198-215.

Baron, L. \& Straus, M. A. (1986, April). 'Four theories of rape: A macrosociological analysis'. Paper presented at the International Congress on Rape, Israel.

Brownmiller, S. (1975). Against our Will, Simon and Schuster, New York.

Burt, M. (1980). 'Cultural myths and supports of rape', Journal of Personality and Social Psychology, 38: 217-230.

Costin, F. (1985). 'Beliefs about rape and women's social roles', Archives of Sexual Behavior, 14: 319-325.

Costin, F. and Schwarz, N. (1987). 'Beliefs about rape and women's social roles: A four-nation study', Journal of Interpersonal Violence, 2: 46-56.

Feild, H. S. (1978). 'Attitudes toward rape: A comparative analysis of police, rapists, crisis counselors, and citizens', Journal of Personality and Social Psychology, 36: 166-179.

Fleming, J. S. and Watts, W. A. (1980). 'The dimensionality of self-esteem: Some results for a college sample', Journal of Personality and Social Psychology, 39: 921-929.

Hormuth, S. E. and Lalli, N. (1988). 'Eine Skala zur Erfassung der bereichsspezifischen Selbstzufriedenheit', Diagnostica, 34: 148-166.

Johnson, E. J. and Tversky, A. (1983). 'Affect generalization and the perception of risk', Journal of Personality and Social Psychology, 45: 20-31.

Koss, M. P. (1988). 'Hidden rape'. In: Burgess, A. W. (Ed.) Rape and Sexual Assault, Vol. II, Garland, New York, pp. 3--25.

Krahé, B, (1991). 'Social psychological issues in the study of rape'. In: Stroebe, W. and 
Hewstone, M. (Eds) European Review of Social Psychology, Vol. 2, Wiley, Chichester, England, pp. 279-309.

Langer, E. J. (1975). 'The illusion of control', Journal of Personality and Social Psychology, 32: 311-328.

London Rape Crisis Centre (1984). Sexual Violence, The Women's Press, London.

Riger, S. and Gordon, M. T. (1981). 'The fear of rape: A study in social control', Journal of Social Issues, 37(4): 71-89.

Robinson, J. P., Shaver, P. R. and Wrightsman, L. S. (Eds) (1991). Measures of Personality and Social Psychological Attitudes, Academic Press, San Diego.

Rosenberg, M. (1957). Occupations and Values, Free Press, Glencoe, IL.

Rosenthal, R. and Rosnow, R. L. (1984). Essentials of Behavioral Research, McGraw-Hill, New York.

Rosenthal, R. and Rosnow, R. L. (1985). Contrast Analysis, Cambridge University Press, Cambridge.

Sanday, P. R. (1981). 'The socio-cultural context of rape: A cross-cultural study', Journal of Social Issues, 37(4): 5-27.

Schwarz, N. (1987). 'Geschlechtsrollenorientierung und die Einstellung zu Gewalt gegen Frauen: Informationsaktivierung als Alternative zu ex post facto-Versuchsplänen', Psychologische Rundschau, 38: 137-144.

Schwarz, N. (1990). 'Feelings as information: Informational and motivational functions of affective states'. In: Higgins, E. T. and Sorrentino, R. (Eds) Handbook of Motivation and Cognition: Foundations of Social Behavior, Vol. 2, Guilford, New York, pp. 527-561.

Schwarz, N. and Bless, H. (1992). 'Constructing reality and its alternatives: Assimilation and contrast effects in social judgment'. In: Martin, L. L. and Tesser, A. (Eds) The Construction of Social Judgment, Erlbaum, Hillsdale, NJ, pp. 217-245.

Schwarz, N. and Brand, J. F. (1983). 'Effects of salience of rape on sex-role attitudes, trust and self-esteem in non-raped women', European Journal of Social Psychology, 13: 71-76.

Schwarz, N. and Clore, G. L. (1988). 'How do I feel about it? Informative functions of affective states'. In: Fiedler, K. and Forgas, J. (Eds) Affect, Cognition, and Social Behavior, Hogrefe International, Toronto, pp. 44-62.

Schwarz, N. and Strack, F. (1981). 'Manipulating salience: Causal assessment in natural settings', Personality and Social Psychology Bulletin, 6: 554-558.

Spence, J. and Helmreich, R. (1972). 'The Attitudes Toward Women Scale: An objective instrument to measure attitudes toward the rights and roles of women in contemporary society', JSAS Catalog of Selected Documents in Psychology, 2: 66.

Tabone, C., Pardine, P. and Salzano, J. (1992, April). 'Why do women accept the rape myth?' Poster presented at the Annual Meeting of the Eastern Psychological Association, Boston.

\section{APPENDIX A}

English translation of the text paragraphs used to increase the salience of rape and assault in Experiment 1

Rape

Woman raped in parking garage! Last Saturday afternoon, 19-year-old Andrea P. was brutally raped by two men in the parking garage at Market Square. Miss P. returned from shopping around 16:30 h and was on the way back to her car, which she had parked on the 2 nd lower level. When she noticed that two men were following her, it was already much too late to call for help. The two men pushed her into a poorly lit corner, and while one of them threatened Andrea P. with a jackknife, the other brutally raped her. The offenders have not been caught yet. 
Assault

Man assaulted in parking garage! Last Saturday afternoon, 19-year-old Andreas P. was brutally assaulted by five young men in the parking garage at Market Square. Mr P. returned from shopping around 16:30 $\mathrm{h}$ and was on the way back to his car, which he had parked on the 2nd lower level. When he noticed that the drunk young men were following him, it was already much too late to call for help. The young men pushed him into a poorly lit corner, and while one of them threatened Andreas P. with a jackknife, the others brutally beat him up. The offenders have not been caught yet.

\section{APPENDIX B}

Text paragraphs used to increase the salience of rape and assault in Experiment 2

Rape

On Thursday, March 16, 1991, at approximately 3:20 p.m., Alicia B., 20 years old, was raped in her own building at 42 Jones Street between Bleecker and West 4th Street. A junior at Hunter College, she worked at Henry and Davidson's as a paralegal. Hoping to acquire some experience before applying for law school, she worked diligently and was given a number of important responsibilities. On the day of March 16, Alicia walked the seven blocks from her workplace to her apartment in order to gather some case files that her supervisor had requested. Upon turning the key and entering through the first doorway of the small brownstone building, she was grabbed immediately by a man who had been hiding behind the door. He threatened her with a knife and forced her down the flight of stairs that led to the basement. He raped her and immediately fled. The police are currently investigating a suspect, but decline to reveal details.

\section{Assault}

On Thursday, March 16, 1991, at approximately 3:20 p.m., Andrew B., 20 years old, was assaulted in his own building at 42 Jones Street between Bleecker and West 4th Street. A junior at Hunter College, he worked at Henry and Davidson's as a paralegal. Hoping to acquire some experience before applying for law school, he worked diligently and was given a number of important responsibilities. On the day of March 16, Andrew walked the seven blocks from his workplace to his apartment in order to gather some case files that his supervisor had requested. He noticed two men loitering and drinking on the sidewalk in front of his small brownstone building. Upon turning the key and entering through the first doorway, he was grabbed immediately by the two men, who had followed him to the door. One threatened him with a knife and the other forced him down the flight of stairs that led to the basement. Although they did not rob him, they beat him up until he lost consciousness. The police are currently investigating suspects, but decline to reveal details. 